\title{
Adquisición y transmisión del conocimiento experto a través de la traducción de las guías turísticas de arquitectura
}

The acquisition and transmission of

expert knowledge through the translation

of architecture guides for tourists

Número especial

- VII -

Discurso turístico, lenguas y traducción

2020
ONOMÁZEIN | Número especial VII - Discurso turístico, lenguas y traducción: 01-17 DOI: 10.7764/onomazein.ne7.01 ISSN: 0718-5758

\section{(C) $($ ii) $\ominus$}

Manuela Álvarez Jurado: Departamento de Ciencias Sociales, Filosofía, Geografía, Traducción e Interpretación, Universidad de Córdoba. ORCID:0000-0003-3243-7672. | E-mail:fflaljum@uco.es

Fecha de recepción: noviembre de 2019

Fecha de aceptación: mayo de 2020 


\section{Resumen}

La indudable relevancia del sector turístico en España ha ido en aumento en los últimos años, lo que ha supuesto una considerable ampliación de la tipología textual, así como un incremento del nivel de exigencia del turista debido a su mayor nivel de conocimientos. En el presente trabajo se plantea la necesidad de que el traductor adquiera el conocimiento experto en el aula de traducción para abordar la traducción de textos turísticos semiespecializados. Se ha elegido la guía de arquitectura ya que presenta una serie de características que la convierte en texto-bisagra entre la guía turística y el texto arquitectónico especializado. La publicación por parte de la Junta de Andalucía de las guías de arquitectura de las ocho provincias andaluzas ha permitido dar a conocer el patrimonio arquitectónico andaluz al turista interesado en ello. Traducidas solamente al inglés, estas guías se han convertido en una herramienta muy útil en el aula de traducción de textos turísticos.

Palabras clave: conocimiento experto; divulgación; traducción; guías de arquitectura.

\section{Abstract}

Spain's tourism sector, of undeniable importance, has been on the rise in recent years, resulting in a considerable expansion in the range of these types of texts along with an increase in tourists' demands with regards to them, due to their greater levels of knowledge. This paper addresses the need for translators to acquire expert knowledge in translation studies in order to properly complete semispecialised tourism texts. An architecture guide was chosen because it features a series of characteristics that place it halfway between a tourism guide and a specialised text on architecture. The publication by the Junta de Andalucía (regional government) of the architecture guides of the eight Andalusian provinces has made it possible to share Andalusia's architectural heritage with tourists interested in it. Translated only into English, these guides have become very useful tools in classes covering the translation of tourism texts.

Keywords: expert knowledge; dissemination; translation; architecture guides. 


\section{Introducción}

La actividad profesional relacionada con el turismo ha adquirido en los últimos tiempos una especial relevancia si tenemos en cuenta tanto la profusa oferta de productos turísticos por parte de las diversas empresas del sector como la creciente demanda de usuarios cada vez más preparados y por tanto más exigentes. Es precisamente este nuevo perfil del usuario turístico, con las ideas muy claras sobre lo que busca y que ha aumentado considerablemente su nivel de exigencia, lo que nos ha llevado a considerar la necesidad de elaborar textos turísticos de calidad, bien documentados, bien redactados y, por supuesto, bien traducidos.

Si tenemos en cuenta que el texto turístico constituye la carta de presentación de un monumento, de un museo, de una ciudad e incluso de un país, la calidad de la traducción de este texto es de gran importancia ya que lo hace visible e incluso lo da a conocer internacionalmente. Así pues, todo texto turístico inicia una comunicación necesaria y demandada por el usuario a través de la cual se le informa, se le documenta, se le aconseja, y la traducción de este texto amplía considerablemente el horizonte de dicha comunicación traspasando fronteras y facilitando que los contenidos del texto turístico estén al alcance de un mayor número de usuarios. Sin embargo, esta finalidad no siempre se cumple: en numerosas ocasiones hemos podido comprobar que se produce una comunicación distorsionada debido a la presencia de indeseables errores de traducción. Estos errores son atribuibles, en la mayoría de los casos, a que numerosas empresas del sector no confían la traducción de sus textos y páginas webs a traductores profesionales, y esto es un hecho constatable, como señala Fuentes Luque (2005, citado por Durán Muñoz, 2009): "Esta baja calidad se debe principalmente a la falta de profesionalización y a la inexperiencia de los que realizan estas traducciones y a la escasa importancia que le otorgan los agentes turísticos que las encargan”. No obstante, nos preocupa igualmente el hecho de que se detecten errores de calibre en traducciones de textos turísticos realizadas por traductores profesionales. Esto nos ha llevado a tomar en consideración la formación del traductor de textos turísticos en el aula y a plantear la necesidad de una propuesta didáctica de actuación en el aula a través del abordaje de textos reales.

Así pues, consideramos que el texto turístico tiene mayor importancia de la que se le otorga en la actualidad, por lo que sería aconsejable que estos textos fuesen redactados y traducidos por especialistas, así como revisados cuidadosamente con el fin de evitar errores que, sin duda, pueden generar en el turista una imagen negativa del país y redundar en una disminución del número de visitantes que van a elegirlo como destino preferente:

Esta baja calidad en las traducciones afecta directamente a la imagen de un país en el extranjero, ya que la traducción de textos turísticos es el medio que utilizan los turistas para aprender, conocer y acercarse al país que visitan. En este sentido, podríamos determinar que el turista recibirá una mala imagen del país si éste no cuida su comunicación con el turista, ya sea de forma escrita o de forma oral. La idea de la imagen de un país, la «marca», ocupa un lugar muy importante en el marketing turístico y en las campañas publicitarias, especialmente para España. Los productos 
turísticos se confeccionan con gran cuidado, ya que con ellos se busca la novedad y el impacto en la audiencia a la que van dirigidos. La marca, además de representar y diferenciar los productos, consigue crear, de forma natural, una imagen psicológica basada en percepciones que aporta un valor añadido a los bienes que acompaña, algo que influye directamente en las decisiones de compra (Durán Muñoz, 2009).

Partiendo de la indudable y consabida vinculación del texto turístico con la traducción, en el presente trabajo hemos centrado nuestra atención en la información que se pone al alcance del turista a través de los textos semidivulgativos relacionados con el turismo arquitectónico y monumental y, sobre todo, en la transmisión de esta información de la lengua del texto original a otras lenguas. Consideramos que la labor del traductor de textos turísticos se reviste cada vez de una mayor complejidad si tenemos en cuenta la creciente oferta turística y por consiguiente la variada tipología textual que esta actividad genera. Por otra parte, el grado de especialización de los contenidos temáticos presentes en los textos turísticos semiespecializados que abordamos en este trabajo requiere una sólida preparación por parte de los divulgadores a la hora de redactarlos y del traductor, quien también debe estar en posesión de este nivel de competencia temática especializada, ya que, como veremos más adelante, este actúa como mediador cultural a través de la traducción de este tipo de textos.

Así pues, el texto turístico se manifiesta a través de discursos específicos que son el resultado de un imprescindible conocimiento experto y es precisamente la formación en el aula de traducción para la adquisición de este conocimiento especializado lo que abordaremos en el presente trabajo.

Tomaremos como punto de partida la siguiente afirmación de Calvi y Bonomi (2008: 181):

El del turismo constituye un sector profesional que, sobre todo en las últimas décadas, ha tenido una enorme expansión y que ha desarrollado, junto a la comunicación reservada a los especialistas, una consistente producción de textos emitidos por los expertos y dirigidos al público, tanto a través del canal oral y de forma directa (en las interacciones cara a cara entre los operadores y los turistas) como por vía escrita y de forma mediada (guías, folletos, artículos periodísticos, etc.). De ahí que la transmisión de los conocimientos especializados ocupe un lugar fundamental en el mundo del turismo.

\section{La especialización del discurso turístico: los textos}

Los conceptos "texto" y "discurso" han sido estudiados separadamente en numerosas ocasiones. Autores como Beaugrande y Dressler (1981) los han diferenciado claramente, mientras que otros han optado por emplear el término "discurso" en detrimento del término "texto" (Maingueneau, 1995, citado en Cabré y Gómez de Enterría, 2006). Sin embargo, para autores como Calsamiglia y Tusón (1999), el texto es concebido como unidad lingüística supraoracional y el discurso como un instrumento de acción social. Coincidimos con Cabré y Gómez de 
Enterría (2006) en considerar ambos términos como sinónimos, aunque admitimos que entre ambos conceptos existe una pequeña diferenciación que lleva a Cabré y Gómez de Enterría (2006) a distinguir entre nivel textual, en el que el texto especializado aparece como preciso, conciso y sistemático, y el nivel gramatical o más concretamente léxico, que incluye unidades específicas o terminología.

El discurso turístico permite y facilita la comunicación entre hablantes, a los cuales vamos a categorizar en función de su nivel de conocimiento experto. De este modo podemos distinguir entre los hablantes o usuarios que poseen un alto grado de conocimiento experto, esto es, los especialistas o expertos en la materia, quienes habitualmente son los productores de los textos turísticos especializados (historiadores, arquitectos, arqueólogos, historiadores del arte, etc.); los hablantes con un grado medio de conocimiento experto, que están representados por los divulgadores o mediadores (aquí incluimos también a los traductores, cuya labor se lleva a cabo en coordinación con el mediador cultural), que se nutren de los discursos orales y escritos producidos por los expertos y actúan como puente entre estos y los hablantes pertenecientes al último grupo al que nos referiremos y que está constituido por los hablantes con un mínimo conocimiento experto e incluso carentes de él. En este último grupo se sitúa el turista que no solo busca una experiencia de ocio, sino que además demanda una información exhaustiva y veraz acerca del destino turístico que ha elegido con la intención de poder disfrutarlo plenamente.

La nueva era de la tecnología ha favorecido ampliamente el contacto y la comunicación entre los turistas a través de blogs, redes sociales y chats presentes en páginas webs. Esto ha contribuido a la mejora de la calidad de las experiencias turísticas, pero, al mismo tiempo, ha supuesto una dificultad añadida para los divulgadores de contenidos y para los traductores de textos turísticos, ya que esta circunstancia ha generado en el turista la necesidad de una información más completa y especializada que difiera de la que le proporcionan los comentarios de otros turistas que han disfrutado ya de la experiencia.

Centraremos nuestro estudio en el hablante que posee un nivel de conocimiento especializado medio, al cual nos hemos referido como divulgador o mediador, y más concretamente en el hablante encargado de trasladar los contenidos especializados del texto turístico origen a otra lengua, es decir, el traductor. Estos contenidos especializados son "de consumo inmediato" por parte del turista y requieren igualmente ser transmitidos de manera rápida, sencilla y directa. Y es ahí precisamente donde se produce la necesaria intervención del divulgador y del traductor, quienes deben estar en posesión de la "pericia" adecuada para elaborar textos divulgativos de fácil acceso. Nos interesa reflexionar sobre la formación del traductor de textos turísticos semiespecializados con el fin de plantear la necesidad de un procedimiento didáctico encaminado a lograr la capacitación de estos profesionales de la traducción para transmitir contenidos turísticos especializados. Nos basamos en nuestra experiencia docente en la impartición de las asignaturas “Traducción de textos publicitarios, turísticos y co- 
merciales" del Grado de Traducción e Interpretación y "Traducción de textos turísticos" del Máster de Traducción Especializada (Inglés/Francés/Alemán-Español), ambas impartidas en la Universidad de Córdoba.

Numerosos autores han coincidido en señalar como rasgos definitorios del texto turístico la hibridez, la multifuncionalidad y la interculturalidad. En efecto, se trata de un discurso especializado en el que coexisten diferentes ámbitos que configuran textos híbridos. La diversidad tipológica de estos textos está a su vez constituida por distintos subtipos atendiendo a la temática dominante en cada uno de ellos. Así pues, además de los folletos turísticos, las guías de viaje y las páginas webs, entre otros muchos tipos de textos, podemos distinguir los siguientes subtipos: textos turísticos publicitarios, textos turísticos jurídicos, textos turísticos informativos, textos turísticos agroalimentarios, textos turísticos culturales, etc. Cada uno de estos ámbitos aporta su especificidad tanto en lo referente a la estructuración sintáctica como a la presencia de una terminología específica. Para Barceló y Jiménez (2011: 33), "[u]na de las principales características de los textos especializados es su especificidad temática, que se refleja fundamentalmente en el uso de una terminología concreta”. Son precisamente estos términos los que actúan como elementos de transmisión del conocimiento experto, como señala Barceló y Jiménez (2011: 33), y "el hecho de desconocer su significado supone un importante obstáculo para la traducción”. Admitimos con Prieto (2008: 8) que el nivel de especialización de un texto no solo depende de la densidad y la diversidad de su terminología especializada, sino también de los elementos discursivos y de la temática presentes en el texto, el ámbito de conocimiento en el que se circunscribe la comunicación y la especificidad de la temática.

La distinción entre las particularidades que definen los lenguajes de especialidad y su relación con la lengua general ha hecho correr ríos de tinta y ha dado lugar a posturas muy controvertidas que finalmente no han llegado a un consenso. Según Cabré (1993), la lengua general está conformada por un conjunto de unidades y reglas (fonológicas, morfológicas, léxicas, sintácticas, semánticas y discursivas) comunes a todos sus hablantes, ya que se trata de elementos utilizados en cualquier conversación cotidiana. Por otra parte, la lengua de especialidad está formada por un conjunto de subcódigos que coinciden parcialmente con los de la lengua común y que, sin embargo, se caracterizan por poseer peculiaridades propias y específicas referidas a la temática, al tipo de interlocutores, a la situación comunicativa, a la intención del hablante, etc.

En los últimos años, el número de estudios sobre los lenguajes de especialidad (LSP) y sobre la enseñanza de lenguas para fines específicos (ESP) ha aumentado considerablemente, sumándose interesantes nuevos estudios a los trabajos ya existentes, como los llevados a cabo por Bueno Lajusticia (2003), Alcaraz, Martínez y Yus (2007), Sánchez Hernández y otros (2008), Santamaría (2010), Pérez-Llantada (2006), Pérez-Llantada y Watson (2011), Suau Jiménez (2001, 2005a, 2005b, 2005C, 2010), Suau y Olivares (2005), entre otros. No deseamos hacer aquí una 
revisión exhaustiva del estado de la cuestión, que ya ha sido suficientemente debatido por numerosos investigadores, sino que nuestro interés se basa en la presentación de las características que definen el texto turístico cultural como discurso especializado para constatar la enorme importancia que tiene para el traductor de guías turísticas semidivulgativas o semiespecializadas (en nuestro caso nos referimos a las guías de arquitectura) la adquisición del conocimiento experto como paso previo e imprescindible a la traducción.

En nuestro interés por demostrar que el texto turístico cultural semidivulgativo o promocional (arquitectónico y monumental) es un texto especializado generado a partir de textos especializados, tendremos en cuenta diferentes factores, entre los que destacan los elementos propios del texto y los que tienen que ver con las condiciones del discurso.

Suárez y Naranjo (2013: 29) hablan de factores extrínsecos e intrínsecos. Según las autoras, los factores extrínsecos hacen referencia a todas las condiciones previas a la producción del texto y tienen presente al emisor o productor del discurso, los destinatarios a quienes va dirigido, el canal de difusión y la finalidad que encierra el discurso. Todos estos factores están interrelacionados, ya que el productor del texto turístico (el divulgador, mediador o el traductor) siempre actúa con una motivación o finalidad: informar y aconsejar al receptor (el usuario o turista), quien, a su vez, ha solicitado previamente información. Entre los factores intrínsecos al texto o elementos propiamente textuales podemos señalar todos los incluidos en los planos cognitivo, semiótico y lingüístico. Así pues, se ha de tener en cuenta tanto la estructura fonológica como la ortográfica y morfoléxica (Suárez y Naranjo, 2013: 30), la estructura textual, así como el paratexto, las imágenes y los recursos multimodales tan relevantes en todo texto turístico.

\section{La transmisión y divulgación del conocimiento turístico especializado}

La realización de cualquier actividad turística relacionada con la cultura lleva asociada una misión educativa y formativa. La visita a un museo o a un monumento suele ir precedida o simultaneada con la consulta de una página web, de un blog, de un folleto o de una guía turística que proporcionan al turista la información necesaria para disfrutar de la experiencia. Sin embargo, la traducción de los textos turísticos relacionados con la arquitectura o la historia del arte no tiene como única finalidad la transmisión de información (si bien este es su principal objetivo), sino que además encierra un propósito aún más ambicioso que se relaciona con la mediación, con la comunicación institucional y con la investigación (Rouxel, 2018: 26). La información contenida en estos textos y transmitida al turista en su propia lengua a través de la traducción suele ser (como ya hemos indicado más arriba) de contenido especializado, por lo que se requiere que el propio traductor actúe como mediador y realice los cambios y adaptaciones necesarios en el texto origen con la finalidad de hacer el texto meta más accesible al receptor. Estas adaptaciones surgen de la necesidad del traductor de trasvasar términos que no tienen equivalencia en la lengua meta (los Ilamados culturemas). 
El descifrado de algunos de los términos especializados que aparecen en el texto o desterminologización es "un fenómeno formal, comunicativo y cognitivo que se manifiesta a través de una serie de procedimientos relacionados con el tratamiento de las unidades léxicas especializadas y centrados en garantizar la accesibilidad de un texto especializado a unos destinatarios no expertos" (Campos Andrés, 2013: 49). Este mecanismo, de gran productividad y eficacia, posibilita la generación de textos más accesibles. Según Zethsen (2009: 809), a los expertos les cuesta trabajo expresar y transmitir de manera sencilla sus conocimientos. Por este motivo García Izquierdo y Montalt Resurrecció (2013: 7) consideran que los traductores están más capacitados que cualquier otro tipo de profesional para llevar a cabo esta tarea debido a sus conocimientos, así como por su familiaridad con todo tipo de textos.

En la transformación del TO y en la elaboración del TM intervienen técnicas de reformulación, recontextualización y desterminologización, gracias a las cuales se hace asequible el contenido textual a receptores no expertos. Tras la extracción de los términos culturales especializados propios de la jerga arquitectónica y de la historia del arte presentes en el texto, se aplican estas técnicas reformulativas y se genera un nuevo texto divulgativo.

Teniendo en cuenta la complejidad y la densidad léxica del lenguaje turístico arquitectónico, la banalización se convierte en una práctica usual siempre que se tenga la intención de poner la información al alcance de receptores no expertos. Desde la definición a la sinonimia pasando por la explicación, la variedad de procedimientos de desterminologización es muy amplia y se adecúa al contenido, al destinatario, a la finalidad y a las características textuales:

- La definición. Definir los términos especializados que forman parte de un texto es una de las herramientas más conocidas y por ende más empleadas. Existen diversas maneras de definir y “la definición resultará más o menos útil en función de si se ajusta a las características del contexto en que se inscribe” (Campos Andrés, 2013: 50). Se han establecido diferentes tipos de definiciones (Mayor Serrano, 2008), algunas de ellas no han sido consideradas como definiciones propiamente dichas, sino más bien "cuasidefiniciones". Parece ser que la definición adquiere una mayor relevancia en determinados géneros expositivos como el manual académico y el artículo divulgativo. En dichos géneros predomina una explicación didáctica, caracterizada por la frecuencia de definiciones y reformulaciones (López Ferrero, 2002: 6).

- La paráfrasis reformulativa. Consiste en el empleo de otras palabras para decir lo mismo. Para ello se pueden emplear los guiones, los paréntesis y se suele utilizar la conjunción "o", o bien se introducen algunos marcadores reformulativos como "es decir".

- La sinonimia. En este caso se suelen emplear términos más cercanos al lector de manera que comprenda con mayor facilidad el término. El sinónimo puede hacer su aparición en el texto entre paréntesis o bien a través de conjunciones o marcadores reformulativos. 
- La hiperonimia. Con este recurso se explica el significado de un término a través de otro que es más general, que lo engloba y además es más conocido. En ocasiones, el hiperónimo puede sustituir al término, de modo que, aunque se pierda precisión en la información recibida, el emisor valora en este caso más la calidad de la información recibida que la cantidad.

- La analogía. En este caso, el emisor o redactor opta por utilizar un término que es más cercano al lector aprovechando su semejanza o identidad con la unidad léxica especializada que se quiere desterminologizar. Se trata de un mecanismo mucho más creativo y que requiere más tiempo para su elaboración, por lo que se suele emplear con menos frecuencia.

- La ejemplificación. Este procedimiento consiste en el empleo de ejemplos para clarificar un término de gran complejidad. Se suelen incorporar paréntesis o expresiones como "por ejemplo".

\section{Adquisición y transmisión del conocimiento experto en el aula de traduc- ción de textos turísticos: las guías de arquitectura}

Los estudios de turismo han adquirido en los últimos tiempos una gran relevancia y están presentes en la mayoría de las ofertas académicas de grado y posgrado de la Universidad española. Por otra parte, también se ha podido observar un considerable incremento de la investigación en este ámbito (artículos científicos, proyectos de investigación, proyectos de innovación docente, manuales, etc.). Se trata de un campo de conocimiento transversal en el que participan distintas disciplinas que generan textos muy diversos. En el Plan de Estudios del Grado de Traducción e Interpretación de la Universidad de Córdoba se contempla la asignatura "Traducción de textos publicitarios, turísticos y comerciales", una optativa de cuarto curso de seis créditos. Asimismo, en el Máster de Traducción Especializada (Inglés/Francés/ Alemán-Español), se imparte la asignatura "Traducción de textos turísticos", de cuatro créditos. Por otra parte, la Universidad de Córdoba cuenta en su oferta académica con un itinerario conjunto del Grado de Turismo y Traducción e Interpretación muy demandado por los estudiantes, que completa todos los años el cupo de admisión en la primera fase. Todo esto viene a incidir en la gran importancia que ha adquirido en los últimos tiempos la formación de traductores en el ámbito turístico.

Coincidimos con Barceló y Jiménez en la idea de que, en la clase de traducción turística, el estudiante como futuro profesional de la traducción debe adquirir el conocimiento experto a través de la traducción de textos especializados y de la terminología de este ámbito (2011: 30). Del mismo modo, Cabré y Estopà (1997: 13) manifiestan que, para adquirir y aumentar este conocimiento, el hablante debe acceder a los discursos o textos especializados y al léxico propio de un área de especialidad. Así pues, se impone la necesidad de que el traductor, en cuanto 
mediador y transmisor del conocimiento especializado, lo adquiera previamente a través del dominio de la terminología especializada. Asimismo, el estudiante de traducción debe trabajar en el aula con textos reales (Estopà y Valero, 2002: 82), lo que le permitirá entrar en contacto con los términos y las unidades de conocimiento especializado. De este modo los términos se convierten en vehículos de transmisión del conocimiento especializado, aunque esta no sea la única vía tanto de adquisición como de transmisión, como hemos señalado anteriormente.

La adquisición del conocimiento experto se lleva a cabo a través del desarrollo de la competencia textual en el futuro traductor, ya que, según Idiazabal y Larringan (2004: 145), a través de su dominio del texto, este adquiere los conocimientos lingüísticos, temáticos y textuales necesarios para una aplicación posterior.

El objetivo fundamental de la formación de traductores es desarrollar en el estudiante la competencia textual junto a la competencia traductora de los documentos empleados en un campo concreto de especialidad (en nuestro caso en el ámbito de la traducción turística arquitectónica y patrimonial), que, según Socorro Trujillo (2012: 303), se encuentra integrada en la competencia traductora. Para el Grupo Pacte (2001: 41), la competencia traductora está integrada por una serie de subcompetencias (comunicativa, extralingüística, de transferencia, instrumental o profesional, psicofisológica y estratégica) que se interrelacionan y varían en función de la combinación lingüística, la especialidad y el contexto.

Coincidimos con Socorro Trujillo (2012), que, a su vez, se basa en García Izquierdo (2011: 10) y en Nord (1991), en que el análisis del texto previo a la traducción es primordial, por lo que se impone la necesidad de un modelo de análisis textual en función de las características lingüísticas y contextuales del texto que se va a abordar y a través del cual se proporciona al estudiante todos los datos necesarios relativos al texto. El método de análisis textual propuesto por Socorro Trujillo (2012: 308) consiste en el estudio lingüístico de los aspectos textuales más relevantes desde una perspectiva traductológica (nivel gráfico, léxico y gramatical).

La adquisición de conocimiento especializado es necesaria para la comprensión del TO y la producción del TM; este se adquiere en buena medida gracias al estudio de la terminología. Como afirma Cabré (citado en Prieto, 2008: 34), "las unidades terminológicas se conciben como unidades del léxico de las lenguas que adquieren un sentido preciso cuando se usan en contextos profesionales definidos temáticamente" y es tarea del traductor discernir el conocimiento especializado del que no lo es.

De este modo, nos interesa señalar la relevancia tanto de la terminología como del texto en la enseñanza de la traducción en el ámbito turístico. Se impone la necesidad de trabajar en el aula con una variedad de textos que sea fiel reflejo de esta circunstancia en la vida real. Como ya han sido estudiadas las tipologías textuales turísticas en numerosas ocasiones y en profundidad, no nos detendremos en enumerarlas una vez más, aunque sí queremos incidir en la necesidad de que el profesor de traducción las incorpore como elemento organizador. 
Hemos centrado nuestro interés en un tipo de texto turístico que presenta unas características peculiares ya que, aunque su destinatario sea el turista, como lo es de otros textos turísticos, se trata de un turista con conocimientos y formación en arquitectura, patrimonio, historia o historia del arte, lo que hace que quiera "ir más allá” y que demande una información "extra”, más detallada y documentada. Nos referimos a las guías de arquitectura.

Consideramos muy acertada la distinción Ilevada a cabo por Jacinto García (2019: 129) entre tres dominios especializados en el ámbito de la historia del arte y la arquitectura: la arquitectura como técnica, la arquitectura como manifestación artística y la arquitectura como reclamo turístico. Es precisamente dentro de este último dominio donde situamos la guía de arquitectura, que no presenta siempre una delimitación clara con respecto a la guía turística, ya que en ocasiones ambas comparten características formales y temáticas que hacen difícil la clasificación (Calvi, 2010: 15) como "obras sobre historia de la arquitectura con un enfoque artístico centrado en diferentes ciudades, o bien como meras guías turísticas especializadas en arquitectura" (Jacinto García, 2019: 130). Atendiendo a la clasificación de Calvi (2010: 23-25), coincidimos con Jacinto García en la inclusión de estas guías dentro del macrogénero de la guía turística, ya que su propio nombre indica que su finalidad es "informar" a un turista muy concreto que muestra interés por la arquitectura y el arte.

Entre estas obras nos interesa destacar las guías publicadas por la Junta de Andalucía desde 1992 dedicadas a cada una de las provincias andaluzas (a excepción de la provincia de Huelva, cuya guía está en proceso de elaboración y se espera que esté terminada en breve). Estas publicaciones en formato papel y digital son el producto de la colaboración de la Junta de Andalucía con los diferentes colegios oficiales de arquitectos de las ocho ciudades. Los editores de estas "guías de autor" manifiestan que la finalidad es que en ellas "se exponga el patrimonio arquitectónico y urbanístico de cada una de las ciudades a través de la visión personal de determinados profesionales que desarrollan en ellas su producción arquitectónica" (Jiménez Mata y Malo de Molina, Guía de arquitectura de Cádiz, 1995). Así pues, la publicación de estas obras se produce debido a la "carencia de documentos que compendien, de manera práctica, información sobre las piezas clave de la arquitectura” (Vázquez Consuegra, Guía de arquitectura de Sevilla, 1992). Martín y Torices, en la Guía de arquitectura de Granada (1998), distingue entre las guías turísticas y las guías de arquitectura: "Sin duda alguna, la ciudad de Granada cuenta con importantes guías y manuales para viajeros. Sin embargo - y a pesar de la calidad y cantidad de monografías eruditas dedicadas a esclarecer su historia urbana y arquitectónica-, escasean las guías consagradas exclusivamente a su patrimonio arquitectónico y en esa línea de divulgación se enmarca la publicación presente".

La guía de arquitectura ha atraído nuestra atención ya que consideramos que se trata de un tipo textual híbrido, versátil y de gran utilidad en el aula. La traducción de este tipo de textos requerirá por parte del alumno una exhaustiva consulta documental en diferentes ámbitos 
(historia, historia del arte, patrimonio y arquitectura), lo que le supondrá la adquisición de un conocimiento experto que, a su vez, deberá aprender a transmitir y a divulgar: "Se ha trabajado con la intención de presentar al público un producto que combine la agilidad y las soluciones prácticas de una guía de bolsillo con el rigor y la calidad de la información” (Martín y Torices, 1998).

Las propias guías incorporan una extensa bibliografía especializada utilizada por los autores, quienes la ofrecen al turista con la intención de que amplíe (si así lo desea) los conocimientos que se le presentan: "La bibliografía empleada se entiende en una triple dimensión: como apoyo documental imprescindible para la calidad del discurso historiográfico, como ayuda al soporte visual que complementa al texto y como información al lector que desee profundizar en determinados aspectos, épocas o estilos de la arquitectura jienense" (Padilla Casuso y Ortega, Guía de arquitectura de Jaén, 2008).

\section{Conclusión}

El turismo cultural ha de ser entendido como "un fenómeno que pone en relación las demandas e intereses de las personas con los bienes culturales que la sociedad quiere preservar" (Orduna y Urpí, 2010: 86). Del mismo modo que hemos señalado que el turismo engloba diferentes disciplinas, el turismo cultural presenta diversas manifestaciones dependiendo del destino turístico y de la finalidad de la actividad que se lleve a cabo: turismo arqueológico, turismo funerario, turismo etnográfico, turismo artístico, turismo gastronómico, turismo enológico, turismo arquitectónico y patrimonial, etc.

El turismo siempre ha estado vinculado a la arquitectura hasta el punto de considerarse que "no puede haber turismo sin arquitectura" (Zamudio Vega, 2013: 58). La arquitectura puede satisfacer dos tipos de necesidades en el viajero: las necesidades pragmáticas referidas al alojamiento (de estas no nos ocuparemos) y las necesidades sensoriales y emocionales que se producen al contemplar un monumento. Es precisamente la arquitectura entendida como atractivo turístico, es decir, aquella que los turistas desean visitar por su valor histórico y su belleza, así como la arquitectura patrimonial constituida por aquellos monumentos que cuentan con un reconocimiento institucional la que ha motivado nuestro estudio, ya que la densidad y especificidad terminológica presente en estos textos requiere de una formación especial por parte del traductor.

Hemos señalado anteriormente la necesidad de que el traductor adquiera el conocimiento especializado para abordar la traducción del texto, pero también debe transmitir el conocimiento experto adquirido, ya que la finalidad del texto turístico consiste fundamentalmente en informar al usuario y esta información puede ser de dos tipos: necesaria y accesoria. La primera está constituida por los datos requeridos por el turista, como pueden ser: horarios de transporte público, de museos, planos orientativos, recomendaciones de hoteles, de res- 
taurantes, etc. Con la demanda de información accesoria el turista pone de manifiesto que quiere "saber más", que quiere conocer la historia, las características técnicas del monumento artístico que visita o del cuadro que contempla.

A través de nuestra experiencia en el aula de traducción de textos turísticos en la que los estudiantes han Ilevado a cabo la traducción al francés de la Guía de arquitectura de Córdoba, hemos constatado lo siguiente:

a) Se ha aumentado la motivación del estudiante por el aprendizaje de la traducción en el ámbito turístico cultural mediante la traducción de textos reales.

b) Se ha dotado al estudiante de las destrezas necesarias para que sea un buen comunicador y divulgador en el ámbito del turismo cultural.

c) Se ha logrado establecer un procedimiento didáctico según el cual el estudiante debe documentarse accediendo a libros especializados en los que se puede encontrar información relativa al ámbito de estudio, a la lectura de artículos en la lengua original escritos por especialistas, a la consulta de bases de datos así como consultar en la medida de lo posible a un especialista.

A la luz de los resultados obtenidos, podemos considerar que el trabajo con textos reales en el aula de traducción turística ofrece grandes y variadas posibilidades. Por otra parte, la traducción de las guías de arquitectura en el aula nos ha permitido comprobar el importante papel como comunicador y divulgador del traductor, quien debe manejar las estrategias de desterminologización para facilitar la comprensión del texto origen. De este modo, ya desde el aula se forma al traductor no solo como mero "trasladador de términos", sino como comunicador y divulgador del conocimiento.

\section{Bibliografía citada}

Alcaraz, Enrique, José Mateo Martínez y Francisco Yus (eds.), 2007: Las lenguas profesionales y académicas, Barcelona: Ariel.

Barceló Martínez, Tanagua, e Isabel Jiménez Gutiérrez, 201ב: "Adquisición de conocimiento experto y terminología en el proceso de enseñanza-aprendizaje de la traducción especializada (ámbitos jurídico y técnico)", Anales de Filología Francesa 19, 25-39.

Beaugrande, RobertA. de, y Wolfgang Dressler, 1981: Introduction to Text Linguistics, Essex: Longman.

Bueno Lajusticia, María Rosario, 2003: Lenguas para fines específicos en España a través de sus publicaciones (1985-2002), Madrid: Proyectos Córydon. 
Cabré Castellvi, María Teresa, 1993: La Terminología. Teoría, metodología, aplicaciones, Barcelona: Editorial Antártida/Empúries,

Cabré Castellvi, María Teresa, y Rosa EstopÀ, 1997: “Formar en terminología: una nueva experiencia docente, Tradterm 4 (1), 175-202.

Cabré, M. Teresa, y Josefa Gómez de Enterría, 2006: La enseñanza de los lenguajes de especialidad: la simulación global, Madrid: Gredos.

Calvi, María Victoria, y Milin Bonomi, 2008: "El lenguaje del turismo: de los textos especializados a la Comunidad del viajero" en Carmen Navarro, Francesca Dalle Pezze, Renzo Miotti y Rosa M. Rodriguez (eds.): La comunicación especializada: terminología y traducción, Bern: Peter Lang, 181-202.

CALvi, María Victoria, 2010: "Los géneros discursivos en la lengua del turismo: una propuesta de clasificación”, Ibérica 19, 9-32.

Calsamiglia Blancafort, Helena, y Amparo Tusón Valls, 1999: Las cosas del decir, Barcelona: Ariel.

CAmpos Andrés, Olga, 2013: "Procedimientos de desterminologización: traducción y redacción de guías para pacientes”, Panace@ 14 (37), 48-52.

Durán Muñoz, Isabel, 2009: "La traducción turística de calidad: una necesidad indudable en la España de hoy”, Mundo Internet. Actas del XII Congreso Iberoamericano de Internet, Telecomunicaciones y Sociedad de la Información, 558-563.

Estopà, Rosa, y Antoni Valero, 2002: "Adquisición de conocimiento especializado y unidades de significación especializada en medicina”, Panacea 3 (9-10), 72-83.

Fuentes LuQue, Adrián, 2005: “La traducción de promoción turística institucional: la proyección de la imagen de España” en Adrián Fuentes Luque (ed.): La traducción en el sector turístico, Granada: Atrio, 59-92.

Garcia IzQuierdo, Isabel, 2011: La competencia textual para la traducción, Valencia: Librería Tirant Lo Blanch.

García Izquierdo, Isabel, y Vicent Montalt ResurReció, 2013: "Equigeneric and intergeneric translation in patient-centred care", Hermes, Journal of Language and Communication in Business 51, 39-54.

Grupo PACTE, 2001: "La competencia traductora y su adquisición”, Quaderns. Revista de Traducció 6, 39-45. 
IdiazABaL, Itziar, y Luis M. LaRringan, 2004: "La competencia discursiva en la didáctica de las lenguas y del plurilingüismo” en BILINGLATAM 2004 First International Symposium about Bilingualism and Bilingual Education in Latin America. Symposium Proceedings, Buenos Aires: ESSARP, 143-152.

JaCinto García, Eduardo José, 2019: "Dibujar la arquitectura con palabras: descripción e imagen en géneros textuales especializados y divulgativos" en Mateo de BeNI (ed.): Imagen y discurso técnico-científico en español. Léxico, obras de especialidad, textos divulgativos, Mantua: Universitas Studiorum Editrice (“Pliegos Hispánicos”), 123-153.

Jiménez Mata, Juan, y Julio Malo de Molina, 1995: Guía de arquitectura de Cádiz, Sevilla: Consejería de Obras Públicas y Transportes, Dirección General de Arquitectura y Vivienda.

López Ferrero, Carmen, 2002: "Reflexiones sobre la enseñanza-aprendizaje de los textos explicativos en la universidad”, Revista de Investigaciones Lingüísticas y Literarias Hispanoamericanas 15 [publicación electrónica en http://web.fu-berlin.de/adieu/vazquez/Reflexiones.pdf].

Martín Martín, Eduardo, y Nicolás Torices AbarCA, 1998: Guía de arquitectura de Granada, Sevilla: Consejería de Obras Públicas y Transportes, Dirección General de Arquitectura y Vivienda.

Mayor Serrano, M. a Blanca, 2008: Cómo elaborar folletos de salud destinados a los pacientes, Barcelona: Fundación Dr. Antonio Esteve.

Nord, Christiane, 1991: Text Analysis in Translation. Theory, Methodology, and Didactic. Application of a Model for Translation-Oriented text Analalysis (traducción del alemán de C. Nord y P. Sparrow), Amsterdam: Rodopi.

Orduna, Gabriela, y Carmen URPI, 2010: “Turismo cultural como experiencia educativa de ocio”, Polis. Revista Latinoamericana 26, 85-108.

Padilla Casuso, José Gabriel, y Rafael Ortega, 2008: Jaén: guía de arquitectura, Sevilla: Consejería de Vivienda y Ordenación del Territorio, Dirección general de Vivienda y Arquitectura.

Pérez Llantada, Carmen, 2006: "Corpus-based research in LSP: Current trends and future prospects. An Interview with Charles F. Meyer (University of Massachusetts, Boston)", Ibérica 12, 145-154.

Pérez-Llantada, Carmen, y Maida Watson (eds.), 2011: Specialised Languages in the Global Village: A Multi-Perspective Approach. Newcastle upon Tyne, Cambridge: Scholars Publishing. L.

Prieto Velasco, Juan Antonio, 2008: Información gráfica y grados de especialidad en el discurso científico-técnico: un estudio de corpus. Tesis doctoral, Universidad de Granada en Andalucía. 
RouxeL, Benjamin, 2018: “Traduire pour le visiteur : l'exemple du Louvre”, Traduire. Une autre perspective sur la traduction, Cahier Traduire l'art 239, 24-33.

Sanchez Hernandez, Purificación, y otros (eds.), 2008: Teaching Specialized Languages: New Contexts, New Challenges (Proceedings of the VII Annual Conference of the European Association of Languages for Specific Purposes (La Manga, 18-20 de septiembre de 2008), Murcia: EditumUniversidad de Murcia.

Santamaría Pérez, Isabel, 2010: "Los atenuantes léxicos en el discurso especializado en español y en catalán” en José Luis Cifuentes Honrubia, Adelina Gómez González-Joder, Antonio Lillo, Francisco Yus Ramos (eds.): Los caminos de la lengua: Estudios en homenaje a Enrique Alcaraz Varó, San Vicente del Raspeig: Publicaciones de la Universidad de Alicante, 887-906.

Socorro Trujıllo, Karina, 2012: "La enseñanza de la traducción directa de la correspondencia comercial: hacia una competencia textual del comercio internacional”, Sendebar 23, 301-320.

Suárez de la Torre, Mercedes, y Mónica Naranjo Ruiz, 2013: "Enseñanza de lenguajes de especialidad: perspectiva didáctica para el análisis y comprensión de textos especializados", Terminàlia 8, 26-26.

Suau Jiménez, Francisca, 2001: "El género y el registro en la traducción del discurso profesional: un enfoque funcional aplicable a cualquier lengua de especialidad”, CULTURELE [WWW.ub.es/ filhis/culturele/tinasuau.html, fecha de consulta: 15 de marzo de 2020].

Suau Jiménez, Francisca, 2005a: "The difficult balance between author's and scientific community's power over research articles in applied linguistics", LSP \& Professional Communication 5 (2), 59-72.

SuAu Jiménez, Francisca, 2005b: "Metadiscourse in Research and Popular Science Articles or how to please the audience: a cross-generic and intra-generic analysis in search of a common metadiscursive core", comunicación presentada en el IPRA gth International Pragmatics Conference. Riva del Garda (Italia).

SuAu Jiménez, Francisca, 2005C: "Matizadores discursivos frente a elementos apelativos y fáticos en artículos científicos" en Luz GIL Salom y Guadalupe AguAdo de CeA (eds.): Estudios sobre las lenguas de especialidad en España. RESLA, Revista Española de Lingüística Aplicada, volumen monográfico, 125-134.

Suau Jiménez, Francisca, 2010: "Metadiscursive elements in the translation of scientific texts" en María Llusa Gea Valor, Isabel García Izquierdo y María José Esteve (eds.): Linguistic and Translation Studies in Scientific Communication. Studies in Language and Communication 86, Fráncfort del Meno: Peter Lang Publishing Group, 243-254. 
Suau Jiménez, Francisca, y María Amparo Olivares Pardo (eds.) 2005d: Las lenguas de especialidad: nuevas perspectivas de investigación. Quaderns de Filologia. Estudis Linguistics 10.

Vazquez Consuegra, Consuelo, 1992: Guía de arquitectura de Sevilla, Sevilla: Consejería de Obras Públicas y Transportes, Dirección General de Arquitectura y Vivienda.

Zamudio Vega, Laura Susana, 2013: "Arquitectura y turismo. La arquitectura como reclamo turístico", Urbano 16 (28), 58-67.

Zethsen, Karen Korning, 2009: “Intralingual translation: An attempt at description”, Meta $54(4), 795-812$. 